\title{
Preparation of amino acid mixtures for cell-free expression systems
}

\author{
Filippo Caschera and Vincent Noireaux \\ Department of Physics, University of Minnesota, Minneapolis, MN \\ BioTechniques 58:40-43 (January 2015) doi 10.2144/000114249 \\ Keywords: amino acid mixtures; amino acid distribution; $\mathrm{pH}$; cell-free transcription-translation
}

Supplementary material for this article is available at www.BioTechniques.com/article/114249.

Here we present a procedure for preparing amino acid mixtures - having both the desired composition and a physiological $\mathrm{pH}$-at high concentrations for cell-free expression systems. Up to $2.1 \mathrm{mg} / \mathrm{mL}$ of active protein was synthesized in batch mode reactions with an all Escherichia coli cell-free expression system. Our method is fast, easy to execute, and economically advantageous compared to expensive commercial kits, making it useful for high-throughput experiments, incorporation of nonstandard amino acids, and cell-free metabolic engineering.

In recent years, the possibility of synthesizing large amounts of protein in vitro has promoted the development of new projects in the field of synthetic biology. These studies rely on cell-free transcription-translation ( $T X-T L)$ systems used as platforms for the construction of complex biochemical systems in vitro, such as gene circuits and metabolic pathways (1-3), phage and ribosome synthesis $(4,5)$, minimal cells $(6,7)$, or artificial cells (8). Cell-free TX-TL is becoming a popular tool for bioengineering that takes advantage of the open nature of in vitro protein synthesis (9).

A cell-free expression reaction is a complex biochemical mixture. Crude cytoplasmic extract is supplemented with synthetic DNA, amino acids, nucleosides, salts, co-factors, and an ATP-regeneration system to recapitulate TX-TL in vitro. The protein concentration is diluted 20 - to 30 -fold compared to in vivo, and the endogenous genetic information (DNA and
mRNA) is removed during preparation. A cell-free TX-TL reaction is an open system with no physical barrier, such as a cell membrane. The system's outputs (i.e., gene circuit performance, metabolic engineering, and protein yield) are studied as a function of concentration levels of each of the aforementioned components, which can be varied over wide ranges as opposed to in vivo.

An all Escherichia coli cell-free expression system was used in the present study. The reporter protein deGFP, a slightly modified version of eGFP (10), was expressed through a transcriptional activation cascade using the following two plasmids (1): pBESTp15A-OR2-OR1-Pr-T7rnap-T500 (0.1 $\mathrm{nM}$ ) to express the T7 RNA polymerase and pIVEX2.3d-deGFP (1 nM) (11). Preparation of highly concentrated stable aqueous solutions of nutrients is one of the key steps in achieving efficient cell-free TX-TL reactions. However, amino acid mixtures of good quality for cell-free TX-TL are complicated to make due to the chemical diversity of the residues. Amino acid mixtures are commercially available, but they are expensive, and either the buffer is unknown or the amino acid concentration is low. Detailed protocols for preparing solutions containing the 20 canonical amino acids at high concentrations have not been reported. Here we present the preparation of amino acid mixtures at high concentration for cell-free TX-TL systems.

We devised a fast and easy procedure to dissolve each of the 20 solid amino acids in an aqueous solution (see Supplementary Material), from which mixtures of arbitrary composition can be prepared. The $\mathrm{pH}$ can be also adjusted between 6.0 and 9.0 (i.e., the physiological range). We used various amino acid mixtures and a custom-made cell-free TX-TL system $(10,12)$ to achieve in vitro active protein synthesis exceeding $2 \mathrm{mg} / \mathrm{mL}$ (11). We show how the concentration of amino acids, distribution (relative abundance of each of the 20 canonical amino acids), and $\mathrm{pH}$ affected protein synthesis yields. It should be noted that T7 RNA polymerase was synthesized in the reaction rather than being added as a purified component. Therefore, our results on protein yields relative to amino acid distributions are specific to the transcriptional activation cascade (both T7 RNA polymerase and deGFP reporter). The amount of T7 RNA polymerase was 100 times smaller than the amount of reporter produced.

The major difficulty in preparing amino acid mixtures is properly dissolving each of the solid chemicals at a high concentration. To make a mixture suitable for in vitro cell-free protein synthesis, the amino acids have to be concentrated in the molar range. We found that this was possible using a solution of $5 \mathrm{M} \mathrm{KOH}$. Potassium is preferred to sodium as a cation in cell-free TX-TL reactions (13). The 20 solid amino acids were dissolved in

\section{METHOD SUMMARY}

The 20 solid amino acids are dissolved at concentrations between 1.6 and $4 \mathrm{M}$ in $5 \mathrm{M} \mathrm{KOH}$, and mixtures containing each of the 20 amino acids are prepared for cell-free expression. The mixtures are diluted in water to achieve a total amino acid concentration between 253 and $268 \mathrm{mM}$. The pH of the resulting aqueous solutions is adjusted with acetic acid. The amino acid mixtures are frozen in liquid nitrogen and stored at $-80^{\circ} \mathrm{C}$. 

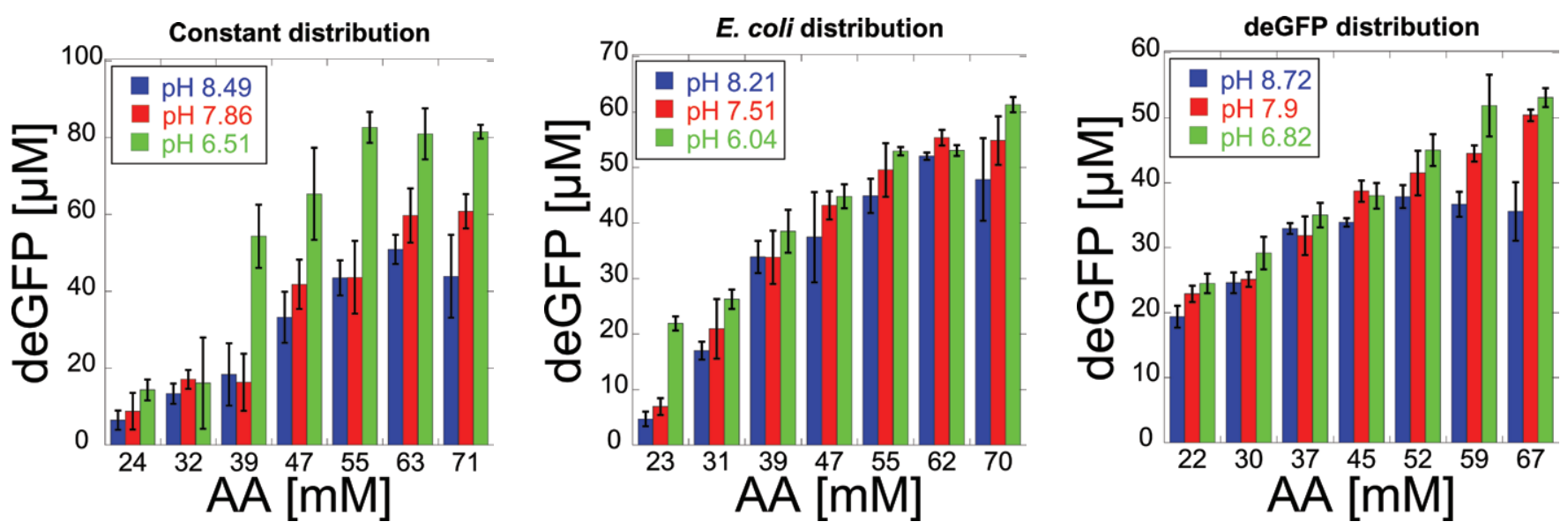

Figure 1. In vitro protein synthesis in batch mode $(12 \mu \mathrm{L})$ measured after $12 \mathrm{~h}$ incubation at $29^{\circ} \mathrm{C}$. deGFP was synthesized through the T7 cascade with $0.1 \mathrm{nM}$ pBEST-OR2-OR1-Pr-UTR1-T7-T500 plasmid, $1 \mathrm{nM}$ pIVEX2.3d-deGFP plasmid, $20 \mathrm{mM}$ K-glutamate, and 2 mM Mg-glutamate. The synthesis was carried out using three different amino acid distributions: (A) constant, (B) E. coli, and (C) deGFP sequence-based (1 mg/mL deGFP = 39.39 $\mu \mathrm{M})$. The final concentration of amino acids in the cell-free reaction is shown on the horizontal axis. Error bars represent the standard deviation from five measurements.

$5 \mathrm{M} \mathrm{KOH}$ to produce concentrations of 1.6-4 M. These stock solutions, stored at $-20^{\circ} \mathrm{C}$ in a liquid phase, can be used for a few weeks. Amino acids were mixed at the desired concentrations, and the mixture was diluted in water. The $\mathrm{pH}$ of the resulting mixture was adjusted with concentrated acetic acid; the solution was then aliquoted in small amounts and stored at $-80^{\circ} \mathrm{C}$, ready for cell-free expression (see Supplementary Material). This is a highly complex and difficult to stabilize mixture as it contains 20 different acids characterized by 20 different $\mathrm{p} K_{\mathrm{a}}$ values. We found that the mixture stability depended on amino acid concentration, composition, and $\mathrm{pH}$. This procedure is fast and inexpensive compared to previous studies where expensive commercial kits were used (12). On average, amino acid mixtures prepared with this method were 30 times less expensive than those prepared with an amino acid sampler kit (e.g., 5 PRIME).

We measured the amount of reporter protein produced in batch mode reactions for nine different amino acid mixtures. In each of the experiments, $T 7$ polymerase and deGFP were expressed (Figure 1). Three different amino acid distributions were used: (i) constant, in which all amino acids were at similar concentrations (120-150 $\mathrm{mM}$ ) in $5 \mathrm{M} \mathrm{KOH}$ (Supplementary Table S1), (ii) E. coli, in which the amino acid concentration distribution was similar to that in E. coli cells (14) (Supplementary
Table S2), and (iii) deGFP, in which the amino acid concentration distribution was based on the relative frequencies of the individual amino acids in the deGFP protein sequence (10) (Supplementary Table S3). In addition, three different pHs were tested: basic, neutral, and acidic. The final total concentrations of amino acids in the cell-free reactions were comparable for the three different distributions. The mixtures were stable at room temperature ( $R T$; $\sim 25^{\circ} \mathrm{C}$ ), during aliquoting ( $20 \mathrm{~min}$ ), and when snap frozen in liquid nitrogen for long storage at $-80^{\circ} \mathrm{C}$ ( 6 months).

The protein yield was quantified by fluorescence using a calibration line, as described previously (11). The amino acid mixture was thawed at RT and added to the cell-free reaction. Amino acid mixtures can show some turbidity after thawing, but this had no effect on the protein yield. For the constant distribution (Figure $1 \mathrm{~A}$ ), the highest yield reached was $83 \mu \mathrm{M}$, which is equal to $2.11 \mathrm{mg} / \mathrm{mL}$ of active protein. This was obtained with a mixture containing $\sim 2.75 \mathrm{mM}$ of each of the amino acids at $\mathrm{pH}$ 6.51. For the E. coli distribution, leucine is the most abundant amino acid (10.5\%) and cysteine the least abundant (1.1\%). The maximum deGFP synthesis was $1.55 \mathrm{mg} / \mathrm{mL}(\sim 61 \mu \mathrm{M})$ with amino acids stabilized at $\mathrm{pH}$ 6.04. The last concentration range was measured for the deGFP distribution mixture. Glycine $(8.9 \%)$ and leucine (8.4\%) were the most abundant, whereas cysteine $(0.9 \%)$ and tryptophan $(0.4 \%)$ were the least abundant. A protein yield of $1.35 \mathrm{mg} /$ $\mathrm{mL}(\sim 53 \mu \mathrm{M})$ was measured at $\mathrm{pH} 6.82$.

Overall, the protein yield mostly varied linearly in relation to the concentration of amino acids used to supply the in vitro TX-TL reaction. With our custom-made cell-free expression system, larger protein yields were reached at slightly acidic $\mathrm{pHs}$ between 6.0 and 6.8. Interestingly, the highest production of active deGFP was observed with the constant distribution mixture. The E. coli distribution preparation was the most stable, as it systematically appeared as a clear solution after gentle thawing at RT. Conversely, the two other mixtures sometimes appeared turbid after being thawed at RT. However, the turbid solutions were well dissolved in the reaction, and protein yields with clear or turbid amino acid mixtures were identical.

In conclusion, we have established a method for preparing complex mixtures of amino acids for custom-made, cell-free expression systems $(1,11)$. This method represents an economical and easy way to solubilize amino acids for in vitro protein synthesis and could be an alternative to the widely used, yet expensive commercial kits. Although only tested for an all E. coli cell-free system, we expect that our protocol could be adapted for other cell-free expression systems, such as T7-based E. coli systems; wheat germ, yeast, plant, and mammalian crude extracts; or platforms developed for the incorporation of nonstandard amino acids (15). 
In addition, the flexibility of our method may allow for combinatorial studies involving machine learning and highthroughput experimentation (16).

\section{Author contributions}

F.C. performed the experiments. F.C. and V.N. analyzed the data and wrote the manuscript.

\section{Acknowledgments}

This research was supported by the Office of Naval Research, United States, award number N00014-13-10074.

\section{Competing interests}

The authors declare no competing interests.

\section{References}

1. Shin, J. and V. Noireaux. 2012. An E. coli cell-free expression toolbox: application to synthetic gene circuits and artificial cells. ACS Synth. Biol. 1:29-41.

2. Hodgman, C.E. and M.C. Jewett. 2012. Cell-free synthetic biology: thinking outside the cell. Metab. Eng. 14:261-269.

3. Bujara, M., M. Schumperli, R. Pellaux, M. Heinemann, and S. Panke. 2011. Optimization of a blueprint for in vitro glycolysis by metabolic real-time analysis. Nat. Chem. Biol. 7:271-277.

4. Jewett, M.C., B.R. Fritz, L.E. Timmerman, and G.M. Church. 2013. In vitro integration of ribosomal RNA synthesis, ribosome assembly, and translation. Mol. Syst. Biol. 9:678.
5. Shin, J., P. Jardine, and V. Noireaux. 2012. Genome replication, synthesis, and assembly of the bacteriophage T7 in a single cell-free reaction. ACS Synth. Biol. 1:408-413.

6. Noireaux, V., Y.T. Maeda, and A. Libchaber. 2011. Development of an artificial cell, from self-organization to computation and selfreproduction. Proc. Natl. Acad. Sci. USA 108:3473-3480.

7. Jewett, M.C. and A.C. Forster. 2010. Update on designing and building minimal cells. Curr. Opin. Biotechnol. 21:697-703.

8. Karzbrun, E., A.M. Tayar, V. Noireaux, and R.H. Bar-Ziv. 2014. Programmable on-chip DNA compartments as artificial cells. Science 345:829-832.

9. Swartz, J.R. 2012. Transforming biochemical engineering with cell-free biology. AIChE J. 58:5-13.

10. Shin, J. and V. Noireaux. 2010. Efficient cell-free expression with the endogenous $\mathrm{E}$. Coli RNA polymerase and sigma factor 70 . J. Biol. Eng. 4:8.

11. Caschera, F. and V. Noireaux. 2014. Synthesis of $2.3 \mathrm{mg} / \mathrm{ml}$ of protein with an all Escherichia coli cell-free transcription-translation system. Biochimie 99:162-168.

12. Sun, Z.Z., C.A. Hayes, J. Shin, F. Caschera, R.M. Murray, and V. Noireaux. 2013. Protocols for implementing an Escherichia coli based TX-TL cell-free expression system for synthetic biology. J. Vis. Exp. 16:e50762.

13. Spirin, A.S. and J.R. Swartz. 2008. Cell-free protein synthesis: historical landmarks, classification, and general methods, p. 1-34. In S. Spirin and J. Swartz (Eds.), Cell-free Protein Synthesis: Methods and Protocols. Wiley-VCH Verlag GmbH \& Co. KGaA, Weinheim, Germany.

14. Lobry, J.R. and C. Gautier. 1994. Hydrophobicity, expressivity and aromaticity are the major trends of amino-acid usage in 999 Escherichia coli chromosome-encoded genes. Nucleic Acids Res. 22:3174-3180.

15. Hong, S.H., Y.-C. Kwon, and M.C. Jewett. 2014. Non-standard amino acid incorporation into proteins using Escherichia coli cell-free protein synthesis. Front. Chem. 2:34.
16. Caschera, F., M.A. Bedau, A. Buchanan, J. Cawse, D. de Lucrezia, G. Gazzola, M.M. Hanczyc, and N.H. Packard. 2011. Coping with complexity: machine learning optimization of cell-free protein synthesis. Biotechnol. Bioeng. 108:2218-2228.

Received 18 August 2014; accepted 22 October 2014

Address correspondence to Filippo Caschera or Vincent Noireaux, Department of Physics, University of Minnesota, Minneapolis, MN. E-mail: filippocaschera@gmail.com_or noireaux@umn.edu

To purchase reprints of this article, contact: biotechniques@fosterprinting.com

\section{GELS • BLOTS ・ MULTIPLEX You Never Had It So Bright!}
BioSpectrum ${ }^{\circledR}$
Imaging System
- Easily excite a wide spectrum of samples from NIR through visible to ultraviolet.
- Optimized for sensitive detection of the faintest signals in chemiluminescence blots.
- Engineered to quickly and automatically capture true high-resolution images.
- Multispectral capability for quantitative analysis of visible and NIR fluorescent western blots.
- Blue light for safe dye detection, white light for protein gels and UV for EtBr gels.
- Simplifies and automates image capture and analysis with templates for repeatability.

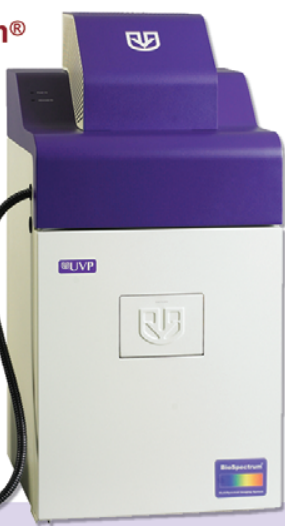

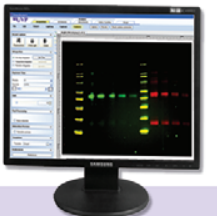

Learn how the BioSpectrum can brighten your images.

uvp.com/bright

\section{NIR • Visible • Ultraviolet • Chemiluminescence}

